\title{
UNIDAD Y ORDEN METAFÍSICOS DEL ORDENAMIENTO JURÍDICO
}

\author{
Metaphysical Unity and ORder \\ OF THE LEgAL SYSTEM
}

\author{
UNIDADE E ORDEM METAFÍSICOS \\ DO ORDENAMENTO JURÍDICO
}

JUAN CARLOS RIOFRÍO MARTÍNEZ-VILLALBA*

* Abogado asociado de Coronel \& Pérez. Profesor titular de Derecho Constitucional y de Derecho de la Información, Universidad de Los Hemisferios, Ecuador. juancarlosr@uhemisferios.edu.ec

RECIBIDO: 30 dE AgOSTO DE 2013. EnVío A PARES: 15 DE SEPTIEMBRE DE 2013. APROBADO POR PARES: 10 DE ABRIL DE 2014. ACEPTADO: 10 DE ABRIL DE 2014.

DOI: $10.5294 / D I K A .2014 .23 .2 .5$

PARA CITAR ESTE ARTÍCULO / TO REFERENCE THIS ARTICLE / PARA CITAR ESTE ARTIGO 


\section{RESUMEN}

El trabajo analiza dos características constitutivas del ordenamiento jurídico: la unidad y el orden. Se trabaja desde la perspectiva de una metafísica realista, bajo el método sistemático, deductivo y cualitativo. Para el efecto, se analizan los cuatro tipos de causas que pueden fundamentar la unidad y el orden del sistema jurídico. La amplitud de este esquema posibilita ir recogiendo al paso los aciertos de los neokantianos, de Kelsen, Austin, Luhmann y otros autores que han estudiado la materia. Se muestran las diferentes nociones de ordenamiento jurídico y sus características principales. Se estudia cómo las cuatro causas metafísicas dan unidad al ordenamiento jurídico y cómo le confieren orden. El artículo termina con unas conclusiones sintéticas.

\section{PALABRAS CLAVE}

Ordenamiento jurídico, unidad, orden, metafísica del derecho, filosofía del derecho. 


\begin{abstract}
Unity and order, two constitutive characteristics of the legal system, are analyzed in this work from the perspective of a realistic metaphysics, based on a systematic, deductive and qualitative approach. The four types of causes that can support the unity and order of the legal system are analyzed to that end. The scope of this method makes it possible to gather along the way the wisdom of the neo-Kantians, Kelsen, Austin, Luhmann and other authors who have studied the subject. The different notions of the legal system and its main characteristics are shown, and the article examines how the four metaphysical causes give unity to the legal system and how they give it order. The article ends with several synthetic conclusions.
\end{abstract}

\title{
KEYWORDS
}

Legal system, unity, order, metaphysics of law, philosophy of law. 


\section{RESUMO}

Este trabalho analisa duas características constitutivas do ordenamento jurídico: a unidade e a ordem. Trabalha-se com base na perspectiva metafísica realista, sob o método sistemático, dedutivo e qualitativo. Para isso, analisam-se os quatro tipos de causas que podem fundamentar a unidade e a ordem do sistema jurídico. A amplitude desse esquema possibilita ir percorrendo paralelamente os acertos dos neokantianos, de Kelsen, Austin, Luhmann e outros autores que estudaram a matéria. Mostram-se as diferentes noções de ordenamento jurídico e suas caracteristicas principais. Estuda-se como as quatro causas metafísicas dão unidade ao ordenamento jurídico e como lhe conferem ordem. Este artigo termina com umas conclusões sintéticas.

\section{PALAVRAS-CHAVE}

Ordenamento jurídico, unidade, ordem, metafísica do direito, filosofia do direito. 
Sumario: 1. Un tema Pendiente; 2. Noción general de “ordenamiento Jurídico”; 3. CaRACTERÍSTICAS METAFÍSICAS DEL ORDENAMIENTO JURÍDICO; 4. LA UNIDAD DEL ORDENAMIENTO JURÍdico; 4.1. LA CAUSA MATERIAL; 4.2. LA CAUSA FORMAL; 4.3. LA CAUSA EFICIENTE; 4.4. LA CAUSA FINAL; 5. EL ORDEN DEL ORDENAMIENTO JURÍDICO; 6. CONCLUSIONES; BiBLIOGRAFía.

\section{UN TEMA PENDIENTE}

La unidad y el orden son dos características constitutivas del orden jurídico ${ }^{1}$ en las que la doctrina ha profundizado aún poco. Llaman la atención las quejas formuladas por Bobbio sobre la materia: "mientras existen muchos estudios particulares sobre la naturaleza de la norma jurídica, no existe, hasta hoy, si no estamos errados, un estudio completo y orgánico sobre todos los problemas que implica la existencia de un ordenamiento jurídico". ${ }^{2}$ Esta queja, repetida por la doctrina posterior $^{3}$ - de manera más enfática que real- ${ }^{4}$ demuestra la escasa atención otorgada al tema. Varias pueden ser las causas de esta falta de atención: una supuesta evidencia, una concepción asistemática del ordenamiento jurídico, o una elevada abstracción del planteamiento que lo hace dificil de abordar.

1 Un sector de la doctrina distingue la noción de "ordenamiento jurídico" de la de "orden jurídico". El primero comprendería el gran conjunto de normas jurídicas vigentes en un lugar y en una época concreta, mientras el orden jurídico sería solo aquel conjunto normativo que rige una determinada área del ordenamiento jurídico. De alguna manera, uno y otro guardarían una relación género-especie. Para otros, el orden jurídico es lo establecido en una sociedad y el ordenamiento son las normas que hacen al orden jurídico. Alchourrón y Bulygin, además, distinguen el "sistema jurídico" que es más estático, del "orden jurídico" que es más dinámico, distinción que ha sido puesta en duda por Zuleta. Cfr. Carlos E. AlchourRón y Eugenio Bulygin, "Sobre el concepto de orden jurídico”, Crítica, 23 (8) (1976), pp. 3-23. Hugo R. Zuleta, "El concepto de orden jurídico en la teoría de Alchourrón y Bulygin”, en Análisis filosófico, 33 (2) (2013), pp. 239-248.

En este trabajo no adoptamos ninguna terminología técnica no muy consensuada, por cierto, sino que tomamos los términos por equivalentes. Consideramos además que el "orden" en sentido metafísico puede predicarse de todos estos conceptos, pues sin ese orden no hay verdadero "orden jurídico", ni "sistema jurídico", ni posibilidad de “ordenamiento jurídico" alguno.

2 Norberto Bobbio, Teoria General del Derecho, Bogotá, Temis, 1992, p. 141.

3 Manrique, en concreto, ha dicho que "la carencia acusada por el italiano al parecer subsiste hoy en día. No hay, hasta donde sabemos — parafraseando a Bobbio al cabo de cuarenta años- una teoría del orden jurídico que pueda parangonarse con la de la norma jurídica. Esta carencia teórica acarrea muchas consecuencias. La más notoria de ellas es que fortalece la tendencia a identificar el orden jurídico con el orden normativo, o por lo menos a suponer que los problemas del ordenamiento jurídico son problemas del sistema normativo"; César Edmundo MANRIgue ZEGarRa, Breve estudio sobre la noción de orden jurídico, en Cuadernos de investigación y jurisprudencia, 6 (2007), p. 8. Y Luhmann, ya específicamente sobre la característica de la unidad del orden jurídico, mencionó que "the unity of the system is simply assumed and no thought is given to the question of how the system acquieres this unity. This is an unsatisfactory state of affairs. It seems to lead to a situation where sociologists leave it to jurists and jurists leave it to sociologists to formulate theories on the unity of law"; Niklas Luhmann, "The Unity of the Legal System”, en G. Teubner (ed.), Autopoietic Law: A New Approach to Law and Society, Berlin-New York, De Gruyter, 1987, p. 13.

4 Como veremos más adelante, ya existen varios autores que han tocado el tema. Cfr. Santi Romano, El ordenamiento jurídico, Madrid, Instituto de Estudios Políticos, 1963; Joseph RAz, El Concepto de Sistema Jurídico. Una introducción a la Teoría del sistema jurídico, México, UNAM, trad. de R. Tamayo, 1986; Manuel Ulloa Ortiz, El orden jurídico, México D.F., UnAM, s.f.; ManRigue, "Breve estudio sobre la noción de orden jurídico", op. cit.; AlchourRón y BulYgin, "Sobre el concepto de orden jurídico”, op. cit.; Ricardo CARACCIOLO, "Sistema jurídico", en Garzón Valdés, E. y Laporta, F. (eds.), Enciclopedia Iberoamericana de Filosofia, vol. 11, Madrid, Trotta, 1996. 
La generalidad del público suele considerar evidentes las cuestiones de la unidad y orden del ordenamiento jurídico. Al darse por descontado su significado y características constitutivas, se pasa directamente al estudio de otras cuestiones más puntuales (v. gr. si el orden jurídico es pleno o tiene lagunas, si es abierto o cerrado, coherente, etc.). Este irreflexivo salto quizá pueda perdonársele al operador del derecho, a quien corresponde hacer un estudio más casuístico y fenomenológico de la disciplina, pero es menos justificable en quienes se dedican a la filosofia del derecho. En realidad ocurre, que estas cosas no son tan evidentes, ni siempre han sido aceptadas.

Por otro lado, la falta de una concepción sistemática del ordenamiento jurídico causa, de manera inmediata, una despreocupación por el tema de la unidad y orden. Si se ve al ordenamiento jurídico como un conglomerado inarmónico de fallos jurisprudenciales, o como un hacinamiento de conductas sociales, o como un producto de diversísimas fuentes de derecho absolutamente heterogéneas, ${ }^{5}$ entonces será difícil - cuando no imposible- descubrir que en tal ordenamiento jurídico existe alguna suerte de orden y unidad.

Nos parece que la razón principal por la que los filósofos suelen descuidar este estudio es porque el tratamiento del "orden" y la "unidad" requieren de un elevado grado de abstracción, tan alto como el metafísico. Otras filosofias que atienden a las causas más inmediatas, como las que hoy están en boga (v. gr. la filosofia analítica, fenomenológica, empirista, etc.), a lo sumo llegan a descubrir una unidad formal o eficiente en el mundo jurídico, que no siempre se da en la realidad. Desde tales puntos de partida, resulta imposible dar una justificación última y completa de una unidad real y de un orden real del sistema jurídico. Siendo la unidad un trascendental del ser que, por tanto, solo se explica bien desde la perspectiva de las causas últimas, y siendo el orden una consecuencia suya, el estudio de la unidad y del orden del ordenamiento jurídico necesariamente debe enfocarse desde la óptica metafísica.

Para adentrarnos en el análisis delinearemos primero la noción de ordenamiento jurídico. Posteriormente abordaremos los conceptos de unidad y orden.

\section{NOCIÓN GENERAL DE “ORDENAMIENTO JURÍDICO”}

La noción de ordenamiento jurídico está intrínsecamente vinculada con el concepto de derecho. Quienes identifican al derecho con la ley (o con la norma) concebirán

5 Según Calvo García, "ni el derecho romano, ni la ciencia jurídica medieval permiten vislumbrar la operatividad definitiva de la concepción sistemática del ordenamiento jurídico. El derecho romano es, sobre todo, un derecho casuístico [...]. La ciencia jurídica de la Edad Media tampoco representa un modelo sistemático de ciencia del derecho [...]. La recepción del derecho romano a finales del siglo XI genera una ciencia jurídica basada en la interpretación del Corpus iuris. La dogmática jurídica medieval es la antítesis de una jurisprudencia sistemática”; Manuel CALvo García, Teoría del Derecho, Madrid, Tecnos, 2000, p. 133. Carpintero explica cómo entró en crisis la concepción medieval del derecho basada en una pluralidad de fuentes normativas (v. gr. derecho canónico, derecho romano, sus comentarios o glosas, las costumbres locales, las resoluciones reales, los estatutos de las corporaciones, la jurisprudencia, etc.). Cfr. Francisco CARPInTERo, Historia del derecho natural. Un ensayo, México, UNAM, 1999, pp. 120 y ss. 
al ordenamiento jurídico como un "conjunto de normas jurídicas" que rigen en un lugar determinado, en una época concreta, o también como la forma en que tales normas se encuentran jerarquizadas. Por otro lado, si se identifica el Derecho con el derecho subjetivo, el ordenamiento será la sumatoria final de los derechos de las personas. En cambio, si se sigue la noción histórica del Derecho como lo justo, el ordenamiento jurídico será el "orden social justo" o el "sistema de relaciones de justicia”. ${ }^{6}$ Consideramos que cada una de estas posiciones destaca un aspecto relevante del ordenamiento jurídico que conviene tomar en cuenta.

Santi Romano, ${ }^{7}$ Norberto Bobbio ${ }^{8}$ y Hans Kelsen son buenos representantes de la noción normativista, que ha gozado de popularidad en los últimos siglos. ${ }^{9}$ Para Kelsen las normas no existen de forma aislada, sino que forman parte de un sistema u "orden normativo". La moral también es, para el autor, un "orden normativo", pero se diferencia del derecho en que este último es coactivo y la moral no lo es. ${ }^{10}$ Quienes identifican el orden jurídico con el conjunto de normas en ocasiones se ven atados en sus razonamientos, porque pronto se percatan de que hay algo más que la norma. Por ejemplo, Alchourron y Bulygin, al definir el orden jurídico como un conjunto de normas, debieron aclarar que "la expresión 'norma jurídica' ha de entenderse en este contexto en un sentido lato (que concuerda con el uso corriente entre los juristas) para abarcar cualquier enunciado que figure en los textos que registran el derecho positivo — constituciones, códigos, leyes, etc.-, sea este normativo o no". ${ }^{11}$

Más completa parece la visión del orden jurídico que parte de la relación jurídica y se remonta hasta sus causas: ahí se encuentra el conjunto de leyes, costumbres, negocios, etc., que causan la relación jurídica, así como los derechos subjetivos, la medida de lo justo, las cosas jurídicas y los sujetos del derecho. Sin duda, el ordenamiento jurídico ordena todas estas realidades. Desde esta perspectiva holística, el ordenamiento jurídico viene a ser el conjunto ordenado de relaciones jurídicas de una sociedad, causadas por unas fuentes comunes de derecho.

6 Ambas expresiones se encuentran en Hervada. En un momento de su vida este autor conceptualizó el derecho como "el orden social justo", aunque luego lo identificó con la cosa justa. Cfr. Miguel SANcho Izguierdo y Javier Hervada Xiberta, Compendio de derecho natural, t. I, Pamplona, Eunsa, 1980, p. 32. Aquí asignamos la noción de "orden social justo" al orden jurídico, lo cual no es totalmente ajeno al pensamiento de este autor, quien ha definido el sistema jurídico como un "sistema de relaciones de justicia”. Cfr. Javier Hervada XIBERTA, Lecciones propedéuticas de filosofia del derecho, $3^{\text {a }}$ ed., Pamplona, Eunsa, 2000, p. 247.

7 Cfr. Romano, El ordenamiento jurídico, op. cit.; Carmen María García Miranda, "La unidad en el concepto de ordenamiento jurídico de Santi Romano", en Anuario da Facultade de Dereito da Universidade da Coruña, 2 (1998), pp. 287-298. Cada autor tiene sus matices. Santi Romano, por ejemplo, lo entiende bajo los parámetros de la sistemática italiana.

8 Cfr. Bobbio, Teoría General del Derecho, op. cit., pp. 173, 181; Carmen María García Miranda, "El principio de unidad en el concepto de ordenamiento jurídico de Norberto Bobbio", en Cuadernos electrónicos de filosofia del derecho, 1 (1998).

9 Esta postura prevalece en la actualidad, sobre todo en el mundo anglosajón. La misma etimología de la expresión Legal System parece avalarlo.

10 Hans Kelsen, Reine Rechtslehre, $2^{\mathrm{a}}$ ed., 1960. La teoría pura del derecho, $2^{\mathrm{a}}$ ed., México, UNAM, trad. de R.J. Vernengo, 1982, p. 75.

11 Alchourrón y Bulygin, "Sobre el concepto de orden jurídico", op. cit., p. 3 (énfasis agregado). 
Pero también se puede extraer la definición de ordenamiento jurídico partiendo del concepto del derecho como res iusta. Para hacerlo, hay que considerar que materialmente "lo justo" únicamente está de manera principal y plena en el intelecto humano, y solo de manera parcial en las cosas externas (como la ley positiva, los objetos del derecho, etc.). ${ }^{12}$ Pues bien, esa misma característica la heredará el sistema jurídico. Junto a otros autores, Hervada ha observado que "el derecho es el sistema racional de relaciones humanas y que el que gobierna no crea la razón de justicia”. ${ }^{13}$ A la par habría que añadir que el ordenamiento jurídico no es exclusivamente un sistema racional, por dos razones: porque la razón es pedida por la realidad extramental y porque la razón, junto a la voluntad, terminan ordenando conductas, sujetos, vastos territorios, cantidad de objetos corporales e incorporales... En sintesis, desde esta perspectiva, el sistema jurídico es un orden de justicia que primero se da en la razón, para luego plasmarse en la realidad extramental.

\section{CARACTERÍSTICAS METAFÍSICAS DEL ORDENAMIENTO JURÍDICO}

No son muchas las clasificaciones hechas sobre las características que todo ordenamiento jurídico debe tener para serlo. Las pocas que existen suelen mencionar las siguientes notas: la autonomía o soberanía, la exclusividad (por la que en un lugar solo hay un ordenamiento jurídico), la primacía por sobre otras reglas sociales de convivencia, la generalidad de sus normas, la plenitud, ${ }^{14}$ la coherencia formal de sus disposiciones — quizá más deseable que real—, la identidad, la organicidad (que determina que las nuevas normas se produzcan bajo los procesos previstos por las antiguas normas), la armonización de varios órdenes (v. gr. nacional, comunitario, internacional) y la "unidad formal".

Aunque cada una de estas características puede considerarse de manera aislada, también es posible descubrir que entre ellas existe una gran interrelación. En la metafisica se ponen al centro las notas del orden y la unidad, que se manifiestan en el resto de características. Por ejemplo, la autonomía presupone la unidad y

12 Recordamos que lo justo está principalmente en el intelecto porque es ahí donde se sopesan los elementos de la relación jurídica y donde se establece cuál es la acción proporcionada por ejecutarse, la cosa justa, el débito, lo que se debe pagar. Hecha esta operación intelectual, los elementos de la relación jurídica (sujetos, objetos, relaciones, etc.) serán también "justos" o "jurídicos", en la medida en que hagan relación a esa cosa justa.

Por otro lado, las partes de una relación como la del derecho son solo eso: partes. No tienen ellas toda la relación, sino solo la medida que servirá para relacionarla con otros extremos. Un lápiz no es derecho, pero tiene un valor que servirá para que la inteligencia lo interrelacione con la cantidad de billetes que hay que pagar para adquirirlo.

13 Javier Hervada Xiberta, Introducción crítica al derecho natural, Pamplona, Eunsa, 2001, p. 114.

14 Esta característica es tenida en mucho por un sector de la doctrina, que considera que "es un principio esencial de todo ordenamiento jurídico, lo mismo si se halla formulado explícitamente, como si no lo está; es una necesidad absoluta de todo orden jurídico; es el principio esencial que condiciona la posibilidad de todo Derecho positivo. A este principio le denominamos: la plenitud hermética del orden jurídico vigente”; Recasens Siches, Tratado general de filosofia del derecho, 6aㅡ. ed., México, Porrúa, 1978, p. 323. Por el contrario, otros sectores la atacan con vehemencia. 
hasta es la misma unidad en acción, porque ella es la capacidad de un individuo (persona, grupo, Estado, etc.) de actuar con independencia de los demás; por otro lado, esa autonomía debe ser ordenada, porque si no lo es, más que autonomía sería azar, correr albures, actuación loca sin ningún sentido, movida solo por causas aleatorias externas. La exclusividad alude de forma externa a la unidad, en cuanto un ordenamiento jurídico no es otro. Por otro lado, la primacía, la generalidad, la identidad, la organicidad y la armonización están fuertemente relacionadas con el orden, porque no hay primacía sin inferioridad, ni género sin especie, ni identidad sin estructura organizada, ni órgano sin una función que cumplir, ni armonía sin una directriz y sin unos grados armónicos, y todo esto implica el concepto de orden (un orden de un más y menos, de género, de fin y de grado).

Repárese, además, que aunque entre unidad y orden existe una estrecha relación, ambas notas nunca se identifican. La unidad es lo primero en la metafísica, pues es un "trascendental del ser": se puede predicar de todo lo que tiene ser, con mayor o menor propiedad. Las cosas son en la medida en que son uno. La unidad se da por algunos principios unitivos o estructurales, que a la vez son los que ordenan la cosa. A continuación veremos cuáles son estos principios y cómo funcionan.

\section{LA UNIDAD DEL ORDENAMIENTO JURÍDICO}

Tomás de Aquino escribió que "una cosa existe en tanto y cuanto es una". ${ }^{15}$ La unidad es un trascendental (una propiedad común) de toda cosa real, y también del ordenamiento jurídico, cuya existencia aquí no cuestionamos. Justamente porque existe esta unidad es posible hablar de un orden jurídico cualquiera; sin unidad, no existiría un ordenamiento jurídico, sino muchos.

Repárese que los trascendentales se pueden predicar de las cosas con diverso grado de propiedad. Hay cosas más unidas que otras: dividir en dos una montaña de arena, no es lo mismo que dividir en dos un perro, una planta o un hombre. En el derecho se discute si el orden jurídico internacional es uno solo, como pretendía Kelsen, o si más bien es un acervo de ordenamientos disimiles. ${ }^{16}$ Bajo la metafísica del ser se puede superar esta visión dicotómica, y comprender que tanto el orden jurídico internacional como el nacional pueden tener un cierto grado de unidad.

Según la metafísica tomista, la unidad solo es posible si en algún extremo del conjunto aparece un principio de conversio ad unum que unifique los demás extremos. No hay unidad, ni orden, sin principio unificador. Corresponde entonces averiguar qué tipo de principio dota de unidad al ordenamiento jurídico.

15 Suma Teológica, I, q. 103, a. 3, sol.

16 A veces se han alzado voces contra la unidad y orden de alguna parte del sistema jurídico, sobre todo en el campo internacional. Cfr. María José FARIÑAS Dulce, "De la globalización económica a la globalización del derecho: los nuevos escenarios jurídicos”, Derechos y Libertades, 8 (2000), pp. 179-194, quien considera que la globalización no conduce a un mayor grado de armonía, unidad y cohesión mundial, sino que genera tensiones, desorden, desigualdad y contingencia. 
Por principio se entiende "aquello de lo que algo procede de cualquier modo que sea”. Con lo cual, todo principio supone una consecuencia o efecto. Los principios pueden ser reales o lógicos: principio real es aquel "ser" del que procede otro "ser", como la fuente es principio del río, mientras que principio lógico es aquel conocimiento del que procede otro conocimiento, como saber sumar es un conocimiento necesario para luego saber multiplicar. El principio apela a la consecuencia, y la causa al efecto.

Desde la perspectiva de la metafísica, nos interesan sobre todo los principios reales, que son las causas de lo real. La causa es una especie de "principio". Tradicionalmente se las ha clasificado en cuatro: la causa material, formal, agente y final. Pues bien, por estos cuatro principios puede darse la unidad del ordenamiento jurídico, según lo veremos.

\subsection{La causa material}

La causa material es aquello de lo cual se hace algo y en lo cual se hace algo. En este sentido, se dice que una mesa está hecha de madera, o una estatua de mármol, y que la madera y el mármol son los "materiales" con los que se hicieron esas cosas. El ordenamiento jurídico materialmente está compuesto por todo lo que se considere jurídico: leyes, sentencias, contratos, costumbres, brocardos o aforismos, derechos subjetivos, cosas justas, etc.

A través de la causa material la unidad se da por poseer todos los extremos la misma materia ("materia" entendida en términos metafísicos). Todo lo que sea ley conforma el conjunto de "las leyes", todo lo que sea justo forma el conjunto de las cosas justas, etc. Como se ve, la mera suma de la materia de las relaciones jurídicas, de las leyes, de las cosas justas o de los derechos subjetivos no nos proporciona más que un orden de agregación. La agregación es una unidad real, pero al mismo tiempo es una unidad muy débil, la más débil de las unidades reales: es la unidad "de montón" que resulta de la mera acumulación o yuxtaposición de las cosas en un conjunto desordenado. La agregación se da, por ejemplo, en los granos de arena de una gran playa o en los papeles de un tacho de basura.

Desde otro punto de vista, se podría decir que el intelecto humano es la base material in genere de los hábitos intelectuales donde subsisten las relaciones de lo justo, los preceptos racionales y el conocimiento de los derechos-subjetivos, con lo cual en él se da una unidad superior a la de la agregación (porque tales accidentes inhieren en él). A una conclusión semejante han llegado los autores neokantianos que pusieron la unidad del sistema jurídico en la conciencia humana, donde radicaba el "deber ser" del derecho. ${ }^{17}$ Esto es verdad, pero con ciertos matices. Sin duda, todos los conocimientos -incluido el jurídico- se emplazan en el intelecto, pero no en un único intelecto, sino en el de varias personas, pues solo hay derecho donde hay alteridad. Por ello, la base intelectual del conocimien-

17 Cfr. Luhmann, “The Unity of the Legal System”, op. cit., pp. 13-15. 
to jurídico tampoco proporciona una gran unidad. Un ejemplo lo demuestra: en un juicio las partes rara vez tienen la misma visión del asunto litigioso, y aún así ambas tienen en su intelecto una cierta noción (errada o justa) de su derecho. Así, si bien es verdad que el intelecto humano causa materialmente una unidad mayor a la de simple agregación, tal unidad solo se da para el individuo; socialmente no hay más unidad que la de la simple agregación de intelectos.

Sin perjuicio de lo anterior, ha de concederse que la sociabilidad humana crea grupos más o menos extensos de gentes que piensan de forma semejante: en grandes territorios se habla una misma lengua, varios pueblos tienen una historia común que recuerdan periódicamente, los vecinos han compartido guerras que los ha sensibilizado de un modo específico... Es evidente que todas esas personas, con una inteligencia parecida, unifican de hecho el ordenamiento jurídico. Ellas mantienen un principio de unidad superior al de la mera agregación, porque en tal unión se mezcla la causa material (unión de distintos intelectos) con la causa formal (piensan de forma parecida), de la que a continuación hablaremos.

\subsection{La causa formal}

La causa formal es la que "conforma". Propiamente es el acto, la perfección o el conjunto de propiedades por el que una cosa es lo que es. Por ejemplo, una mesa tradicional tiene por causa formal su figura cuadrada y su color café. La causa formal puede ser intrínseca o extrínseca. La causa formal extrinseca también se llama "causa ejemplar" y se da cuando una cosa se hace a ejemplo de otra, como las monedas romanas tenian la figura del César.

El orden jurídico posee muchos elementos que le dan una forma específica, pero como su base es el derecho, en esencia tendrá la misma forma del derecho. Tradicionalmente se ha entendido al derecho de tres maneras: como res iusta, como derecho subjetivo y como ley. La causa formal del derecho-relación (de lo justo) es la de ser un accidente relación: ${ }^{18}$ en concreto, para la doctrina aristotélico-tomista, es una relación de una cierta igualdad que se da entre aquello de lo que se es titular y lo que se debe: lo justo es producto de un "ajustamiento" de cuentas. ${ }^{19}$ La forma del derecho-subjetivo también es la de ser un accidente que relaciona la cosa, la facultad y su titular. En cambio, la forma de la ley es la de ser un "precepto racional".

18 Como se sabe, los accidentes son "modos de ser de la sustancia", que es donde inhieren. Por eso, a diferencia de la sustancia a la que corresponde ser en sí, a los accidentes corresponden ser en otro. Aristóteles los clasificó en: cantidad, cualidad, acción-pasión, ubi (dónde), situs (estructura espacial interna), quando (situación temporal), relación y habitus (tener, que es un accidente exclusivo del ser humano).

19 En este sentido, Tomás de Aquino dice que "lo primero de la justicia, dentro de las demás virtudes, es ordenar al hombre en las cosas que están en relación con el otro. Implica, en efecto, cierta igualdad, como su propio nombre manifiesta. Vulgarmente se dice que las cosas que se igualan se ajustan. Ahora bien: la igualdad se establece en relación con otro. [...] En nuestras acciones se llama justo a aquello que, según alguna igualdad, corresponde a otro, como la retribución del salario debido por un servicio prestado”; Suma Teológica, II-II, q. 57, a. 1, sol. 
Una cierta unidad se consigue por la vía de la formalidad legal, donde lo justo suele hacerse a ejemplo con la forma de un patrón. ${ }^{20}$ Un sistema jurídico puede generarse a partir de un modelo, de una norma ejemplar (v. gr. la Constitución) a la que todo el ordenamiento se debe adecuar formalmente. Esa es la unidad planteada por Kelsen, ${ }^{21}$ Bobbio, ${ }^{22}$ y por los adherentes al positivismo normativo, ${ }^{23}$ que ya Schmitt criticó por su desconexión con la realidad. ${ }^{24} \mathrm{Y}$ en efecto, esta unidad del orden jurídico viene a ser más una aspiración, una meta que deben conseguir los jueces constitucionales y los operadores del derecho, que una realidad, pues los hechos demuestran que existen normas contradictorias, lagunas legales, casos de excepción, etc. ${ }^{25}$ Ciertamente, estamos ante una unidad mayor que la meramente material, aunque todavía se asimila a la sola agregación, como lo es la de un conjunto de granos que tienen la misma forma.

Varios juristas modernos, embelesados con el ideal de aquella ciencia sistémica que resolvería todo, concibieron al derecho como un ordenamiento de justicia teórico, conformado por unos primeros axiomas o principios de los cuales se deducirían el resto de principios y reglas. Pufendorf, Wolf y Leibniz se empeñaron en diseñar sistemas de reglas que supuestamente codificarian todo el derecho. Este sistema racional de preceptos gozaría de una gran unidad y orden, que no serán sino unidad y orden meramente formal y teórico obtenidos por la vía de la deducción intelectual. ${ }^{26}$ MacIntyre observará que tales sistemas pretendian fundamentar una

20 Según la doctrina metafísica más aceptada, la causa ejemplar es una especie de causa formal (en concreto, es una causa formal extrinseca).

21 Muy significativas son las palabras de Errázuriz acerca de la unidad formal conseguida por Kelsen: "la novedad de la Teoría Pura no se encuentra en el descubrimiento de la jerarquía normativa, idea muy antigua en la vida del derecho, de la cual otros juristas, como Bierling, se habian ocupado ya ampliamente. Lo peculiar de la Teoría Pura es la función que atribuye a esa jerarquía, tratándola de acuerdo con su enfoque formalista, y en función de los problemas de la unidad y el fundamento de validez del derecho". Carlos José Errázuriz Mackenna, La teoría pura del derecho de Hans Kelsen, Pamplona, Eunsa, 1986, p. 233.

22 Cfr. BobBio, Teoria General del Derecho, op. cit., pp. 154-181.

23 Ciertamente, existen otras posturas sobre la unidad en el positivismo. En Hart, por ejemplo, el elemento que dota unidad y orden al sistema jurídico ya no es la norma suprema, sino la rule of recognition. Cfr. Hebert HarT, The Concept of Law, Oxford, Clarendon Press, 1961. En cualquier caso, estamos ante elementos formales, más o menos discutidos, que alguna unidad otorgan al sistema jurídico.

24 "No hay ningún sistema constitucional cerrado de naturaleza puramente normativa, y es arbitrario conferir trato de unidad y ordenación sistemáticas a una serie de prescripciones particulares, entendidas como leyes constitucionales, si la unidad no surge de una supuesta voluntad unitaria”; Carl ScHмIтT, Teoría de la Constitución, Madrid, Editorial Revista de Derecho Privado, 1934, p. 11. Recordamos que para Schmitt "una Constitución no se apoya en una norma cuya justicia sea fundamento de su validez. Se apoya en una decisión política surgida de un ser político, acerca del modo y forma del proprio ser. La palabra "voluntad" denuncia - en contraste con toda dependencia respecto de una justicia normativa o abstracta - lo esencialmente existencial de este fundamento de validez"; ibid., p. 87.

$25 \mathrm{Al}$ respecto, es muy clara la apreciación de García Miranda, que al analizar el principio de unidad de Bobbio, apoyado sobre la interpretación de la norma fundamental, concluye que "sin embargo, este último factor de unidad no se consigue de forma plena o absoluta, pues existen siempre supuestos de antinomias o lagunas, pese a los esfuerzos del intérprete del Derecho a la hora de cumplir el mandato legal de resolver el caso controvertido, optando entre las frecuentes normas antagónicas o acudiendo, en caso de lagunas, a los criterios de autointegración o heterointegración"; García Miranda, "El principio de unidad en el concepto de ordenamiento jurídico de Norberto Bobio", op. cit.

26 Cfr. Michel Villey, Los fundadores de la Escuela Moderna del Derecho Natural, Buenos Aires, Ghersi, trad. C. R. Sanz, 1978, pp. 99-100. 
ética y unas normas que en el fondo procedian de una tradición, sin aceptar la concepción teleológica de una naturaleza humana que daba sentido a esa ética. ${ }^{27}$ Algo semejante sucede con la identidad formal de los múltiples derechos subjetivos y de las diversas cosas justas que existen en las relaciones jurídicas que conforman el ordenamiento jurídico: otorgan una cierta unidad al conjunto, pero se trata solo de una unidad formal.

\subsection{La causa eficiente}

La causa eficiente es aquella que produce algo o provoca la modificación de una sustancia; es el principio del que fluye primariamente cualquier acción que hace que algo sea, o que sea de algún modo. La causa eficiente inmediata suele ser una acción, para incluir luego al sujeto que realizó esa acción. La causa de una cirugia estética es directamente la operación y también, con alguna posterioridad mental, el médico que operó.

El principio de unidad del ordenamiento jurídico más palpable viene por la vía de la causa eficiente, por los agentes productores del derecho. A más productores de derecho autónomos, menos unidad; en cambio, si hay un solo rey o gobernador, habrá un solo derecho, un solo orden jurídico. Lo anterior, obviamente, se dice bajo el entendido de que el rey o gobernador tengan un poder concentrado efectivo y no sean meros cargos de honor.

Varios autores hablarán de la causa eficiente, a su modo. Caso paradigmático es el de Kelsen, que al inicio de su carrera consideraba que la producción del derecho era una cuestión "metajurídica", y atribuía la unidad del orden jurídico a la voluntad del Estado (que para él era el punto final de imputación de los efectos jurídicos). ${ }^{28}$ Sin embargo, su posición fue cambiando y poco a poco la "nomodinámica" fue apareciendo hasta mostrarse finalmente como el fundamento de la unidad del ordenamiento. ${ }^{29}$

27 Cfr. Alasdair MacintYRe, Tras la virtud, Barcelona, Crítica, trad. de A. Valcárcel, 1987, caps. 1-3.

28 En este sentido, afirmó que "el Estado como sujeto de estos actos, no es más que una expresión personificadora de la unidad de este orden. La referencia de estos actos a la unidad del orden -en méritos de la norma que estatuye el acto en cuestión- constituye la imputación al Estado. El Estado es el punto final común de imputación de todos los actos estatales (cualificados así, de un modo específicamente normativo), es el punto común de encuentro para la imputación de todos los hechos cualificados como actos del Estado"; Hans KeLsen, Compendio de Teoría General del Estado, 1925, México, Colofón, trad. de L. Recasens Siches y J. de Azcárate, 2007, p. 117. Como vimos en la nota 24, Schmitt mantiene una posición similar.

29 En 1913, Kelsen ya hablaba del devenir de la norma (en "Zur Lehre vom öffentlichen Rechtsgeschäft", Archiv des öffentlichen Rechts, 31 (1913), pp. 53-98, y la función de la norma básica en este proceso se expondría al año siguiente (en "Reichgesetz und Landesgesetz nach der österreichischen Verfassung”, en Archiv des öffentlichen Rechts, 32 (1914), pp. 202-245, 390-438), siendo más ampliamente expuesta en "El problema de la soberanía" (Das problem der Souveränität, Tubinga, J.C.B. Mohr, 1920). En el prólogo de la segunda edición de "Problemas capitales" (Hauptprobleme, Tubinga, J.C.B. Mohr, 1923) Kelsen dejará constancia de esta nueva perspectiva que se abría en la Teoría Pura del Derecho, aludiendo a una serie de artículos que Merkl publicó entre 1917 y 1923 y que influyeron decisivamente en esta materia, hasta el punto de que Kelsen calificó a su discípulo de "cofundador" de la Teoría Pura del Derecho. Al respecto, cfr. Gabriele Kucsko-Stadlmayer, "La 
Para quienes identifican el Derecho con la ley, la unidad del sistema solo podrá venir por la unidad de producción de normas. En su peculiar visión autopoiética del orden jurídico, Luhmann tuvo el acierto de considerar que la unidad al sistema se fundamentaba en la producción estructuralmente organizada de normas jurídicas (en el fondo, el Estado sería el sujeto que le daría la unidad). ${ }^{30}$ Sin embargo, por considerar "abierto" (indeterminado) al sistema jurídico, dedujo que en él no podia existir ningún tipo de orden, ${ }^{31}$ con lo que a la postre terminó también desarticulando la unidad del sistema. Además, Luhmann olvidó tomar en cuenta que dentro del Estado pueden existir varias autoridades con similar poder. De hecho, hoy se tiende a repartir los poderes de manera balanceada, dividiéndolos entre las distintas autoridades, sin darle a ninguna una supremacía absoluta. Tal reparto resquebrajaría la unidad eficiente del sistema jurídico. La cuestión es especialmente clara en Austin, para quien la unidad del sistema se basa en que toda ley debe venir de actos legislativos realizados por una persona, o por un conjunto de personas que actúen como uno solo. ${ }^{32}$ Sin embargo, esto no se verifica hoy en día. Más problemas para solventar la unidad del orden jurídico tendrán quienes para el análisis jurídico parten de la noción de derecho subjetivo (v. gr. los precursores del individualismo o del anarquismo). Célebres autores como Hobbes, Locke y Rousseau lo han intentado recurriendo a imágenes como las del Leviatán o el pacto social. Hobbes recurre al mítico monstruo del Leviatán para explicar cómo todos los ciudadanos entregan sus derechos mediante un cierto contrato a un ser supremo que aplasta los excesos de los individuos; la teoría contractualista de otros autores destaca más que los derechos se transfieren, pero a la vez quedan en los individuos. Sin embargo, ni el monstruo mitológico deja de ser una metáfora mientras no encuentre apoyo en la realidad, ni el pacto social una fábula hasta que se demuestre dónde se ha firmado o cómo se ha suscrito. ${ }^{33}$

La linea de pensamiento que mejor explica la unidad eficiente del sistema jurídico es la que parte del análisis del Derecho-relación. Como se verá, ella recoge los aciertos de quienes consideran que la ley o los derechos-subjetivos son los que dotan de unidad al orden jurídico. La explicación la daremos tomando en cuenta las diferentes causas del derecho-relación, que a saber son: la operación intelectual, las concepciones jurídicas, la realidad extramental y la actuación jurídica. Vayamos, pues, en el mismo orden.

contribución de Adolf Merkl a la teoría pura del derecho", en Revista de la Facultad de Derecho de México (2005), pp. 243-258.

30 Luhmann, "The Unity of the Legal System", op. cit., pp. 14-32.

31 Cfr. texto citado en la nota 48.

32 Al hablar sobre el sujeto soberano, Austin señala que "in every society political and independent the sovereign is one individual or one body of individuals"; John Austin, The Province of Jurisprudence Determined, New York, The Noonday Press, 1954, p. 246, donde se entiende que la soberania implica un poder único y unido. Raz ha observado que "Austin's criterion of identity, we may say, is based on the principle of legislative origin and assumes that all the laws of the system have one persistent ultimate source"; RAZ, El Concepto de Sistema Juridico, op. cit., p. 22.

33 A veces se dice que tal pacto se plasma en la aceptación de la constitución, en algún referéndum, etc. Siendo verdad que una parte del pueblo presta su anuencia para regirse por estas normas, la verdad es que otra parte del pueblo no lo hace, y que en la gran mayoría de los casos uno nace y crece bajo un régimen constituido y bajo unas normas que no se aceptaron. 
a) La causa eficiente más inmediata del derecho-relación era la prudente operación intelectual que relaciona lo justo. En cada relación jurídica deberá haber una operación intelectual distinta numérica y formalmente, ${ }^{34}$ para hallar lo justo en cada caso; con lo cual, tal multitud de operaciones intelectuales no puede justificar una fuerte unidad del sistema jurídico. En cambio, sí lo puede hacer la virtud de la prudencia, a su modo. La prudencia es un hábito intelectual de la razón práctica que ayuda a la inteligencia a hallar los fines (que por serlo son "buenos") y los medios convenientes para llegar a ese fin, para dar a cada uno "lo justo". ${ }^{35}$ Por tanto, ella necesariamente debe darse en toda relación de justicia donde es necesario descubrir la verdad de "lo justo", para luego poder darlo. Sin la prudencia el Derecho-relación no nace. La prudencia, además de ser causa eficiente del Derecho, determina formalmente lo que será el Derecho-relación. ${ }^{36}$

b) Las concepciones jurídicas son el conjunto de conocimientos previos que determinan la operación intelectual que relaciona por primera vez lo justo (el derecho-relación). ${ }^{37}$ Cuando las concepciones jurídicas son generalizadas es decir, no aisladas, también son causa de la unidad del orden jurídico. Las costumbres populares, las tradiciones y la cultura centenaria definen radicalmente lo que es el derecho en cada sitio. Si las concepciones jurídicas son erradas, serán causa de unidad de un orden jurídico errado, cuya unidad es más deficiente que la del orden jurídico verdadero, porque el mal es menos "efectivo" (o eficiente) que el bien. Además, como lo falso se contradice con la verdad, las ideas jurídicas erradas se enfrentarán con las correctas que esa misma sociedad mantenga.

34 Es distinta formalmente porque en cada relación jurídica la inteligencia juzgará extremos distintos, de los que toma su forma. La operación mental que un banquero hace en su negocio de títulos valores es muy distinta a la que el labrador efectúa sobre sus papas.

35 Acerca de esta virtud el Aquinate decía: "la prudencia es la virtud más necesaria para la vida humana. Efectivamente, vivir bien consiste en obrar bien. Pero, para que uno obre bien no solo se requiere la obra que se hace, sino también el modo de hacerla, esto es, que obre conforme a recta elección, y no por impulso o pasión. Mas como la elección es respecto de los medios para conseguir un fin, la rectitud de la elección requiere dos cosas, a saber: el fin debido y el medio convenientemente ordenado al fin debido. Ahora bien, respecto del fin debido, el hombre se dispone convenientemente mediante la virtud que perfecciona la parte apetitiva del alma, cuyo objeto es el bien y el fin; y respecto del medio adecuado al fin debido, necesita el hombre disponerse directamente mediante el hábito de la razón, ya que el deliberar y elegir, que versan sobre los medios, son actos de la razón. Por consiguiente, es necesario que en la razón exista alguna virtud intelectual que la perfeccione convenientemente respecto de los medios por elegir para la consecución del fin, y tal virtud es la prudencia. La prudencia, pues, es una virtud necesaria para vivir bien"; Suma Teológica, I-I, q. 57, a. 5, sol.

36 Sobre el rol de la prudencia en el derecho recomendamos Javier HERvadA XIBERTA, "Reflexiones acerca de la prudencia jurídica y el derecho canónico", en Revista Española de Derecho Canónico, XVI (1961), pp. 415-451.

37 Estos conocimientos previos que influyen en la evaluación de lo que es el derecho, de lo que es justo en cada caso, comprenden: el conocimiento del mundo, de la ciencia jurídica y de los extremos de la relación jurídica que intelectualmente se relacionarán. Dichos conocimientos influyen decisivamente en el derecho. Por ejemplo, no actúa igual quien conoce bien un deber, que quien lo conoce a medias, que quien lo desconoce. Por eso, a un menor se le perdona más que a un mayor, a un ignorante sin culpa más que a un experto en la materia. El conocimiento abstracto de la ley incide eficazmente en el intelecto del juez que juzgará sobre lo justo y, consecuentemente, sobre la forma que tenga el hábito intelectual relacional. 
c) La realidad extramental también es causa eficiente de una unidad muy fuerte del sistema jurídico. Ella "mide" y determina el pensamiento: el derecho se construye mentalmente sobre cosas reales, no sobre mitos, fábulas o leyendas. El intelecto conoce la forma de la realidad, ausculta en su ser y en sus potencialidades, descubre para qué sirven las cosas, cuáles son sus fines... para luego valorarla jurídicamente creando una concepción jurídica y discerniendo lo que es justo en cada caso.

La realidad extramental comprende el entorno corporal, las cosas, las acciones externas y las personas. Cada uno de estos elementos da una cierta unidad al sistema jurídico. La que menos unidad proporciona es el entorno corporal que es de naturaleza más circunstancial y cambiante, con lo que difícilmente podrá dar por largo tiempo unidad al orden jurídico. Las cosas y las acciones externas varían menos, y son capaces de unificar alguna rama del derecho (v. gr. el derecho de bienes raíces, el derecho informático, el derecho penal, el derecho de los contratos, etc.), mas carecen de fuerza para dar unidad a todo el universo jurídico. El único extremo con suficiente fuerza y cohesión para dar unidad a todo el ordenamiento es la persona humana, porque es ella la que concreta y mide lo justo; en ella comienzan y finalizan todas las relaciones jurídicas y sociales. ${ }^{38}$

d) Por última causa eficaz tenemos la "actuación jurídica", que comprende todo el actuar volitivo humano que produce efectos jurídicos: ahí se encuentran la ley, los actos y negocios jurídicos, la jurisprudencia, etc. Sin duda, ella también proporciona una cierta unidad al sistema jurídico, en la medida en que es eficaz. No son eficaces las leyes, los contratos, las sentencias, etc., que no se conocen; por otro lado, tienen una eficacia mermada aquellas decisiones que no se cumplen. ${ }^{39}$ Son más eficaces las normas más reales, verídicas y racionales, que las más irreales, falsas e irracionales (caben grados), porque metafísicamente bonum difusui sui, lo más perfecto es lo más activo, lo racional fácilmente disuade, mientras lo errado, tuerto o confuso, escaso o ningún efecto jurídico genera. En ocasiones hay la tentación del desaliento pesimista: uno ve el panorama de su país y todas las leyes vigentes son defectuosas. Se ha de admitir, entonces, que toda obra humana -incluida la ley - es perfectible; pero a la vez conviene observar que las buenas leyes, las que el pueblo entiende mejor por ser más racionales, se cumplen mejor que las malas leyes que el pueblo instintivamente busca evadir.

38 El hecho de compartir la misma naturaleza implica una cierta unión. Se habla de "la comunidad humana" y de "la humanidad" no como un conjunto de mera agregación de individuos, sino como "la familia humana" que tiene un tronco común. Tomás de Aquino, inspirándose en un principio enunciado por Porfirio (s. III-IV), según el cual "por la participación en la misma especie, todos los hombres forman como un solo hombre", comenta: "así como en una persona hay muchos miembros, así en la naturaleza humana hay muchas personas”; TomÁs dE Aguino, Compendio de Teología, c. 196; cfr. In Epist. ad Rom., c. 5, lect. 4.

39 La violación de la ley y el incumplimiento de un contrato son hechos que justifican la intervención de la autoridad para que con su poder haga que se cumplan. Pero aunque la autoridad no tuviera potestad coactiva suficiente para obligar su cumplimiento, el derecho ya ha nacido; por eso se puede calificar de "injustos" o "contrarios a derecho" a aquellos actos reprobables. Es decir, la ley y el contrato incumplidos ya han sido causa eficaz del derecho. 
Por otro lado, observamos que están llamadas a ser más eficaces las normas más abstractas y las normas superiores: las más abstractas porque abarcan más casos de la realidad, y las normas superiores, porque condicionan a un mayor número de supuestos (leyes, actos, negocios, etc.). Los actos y negocios, simples o jurídicos, así como la jurisprudencia especialmente la que no crea precedente, tienen una eficacia más puntual, y por tanto carecen de fuerza suficiente para unificar todo el sistema jurídico.

Considerada la actuación jurídica desde el punto de vista de quien actúa, habría que decir algo similar: las autoridades menores poca pujanza tienen para con sus actos unificar la totalidad del orden jurídico; en cambio, las autoridades mayores la tienen en mayor grado. En la monocracia de cualquier índole (v. gr. dictadura, monarquia hereditaria, monarquía constitucional, etc.) la autoridad suprema unifica significativamente el sistema jurídico. El Aquinate aludió a esta causa eficiente cuando, para fines teológicos, observó que "necesariamente debemos afirmar que el mundo está gobernado por uno solo" y que "la multitud es mejor gobernada por uno que por muchos". ${ }^{40}$

La actuación jurídica parte siempre de una concepción del derecho: la voluntad solo puede decidir sobre lo que le presenta el intelecto. Por eso, si la concepción jurídica es errada, también lo será la actuación jurídica, y al revés. Veritas liberavit vos. Pongamos un ejemplo: aunque la Constitución consagre a todos los ciudadanos el derecho a la seguridad social, quienes lo desconozcan en la práctica se verán impedidos de beneficiarse de ella. Cuando salgan de su ignorancia, podrán acudir a las puertas del seguro social para cobrar los valores a los que por ley tienen derecho.

\subsection{La causa final}

La causa final es la meta, el objetivo, el punto de llegada, la proyección hacia la que se mueve el agente (el que actúa como causa eficiente). Para el agente el fin se identifica con lo bueno. Hay dos clases de cosas buenas: lo bueno en sí, que se busca por sí mismo, y lo bueno por otro (el medio o instrumento) que se busca

40 Suma Teológica, I, q. 103, a. 3, sol. La solución completa al artículo dice: "necesariamente debemos afirmar que el mundo está gobernado por uno solo. Siendo el fin del gobierno del mundo lo que es esencialmente bueno, que es lo mejor, necesariamente el modo del gobierno del mundo ha de ser también el mejor. Y el mejor gobierno es el de uno solo, pues gobernar es dirigir los gobernados al fin, que es un bien. La unidad es esencial a la bondad, como prueba Boecio por el hecho de que, como todas las cosas buscan su bien, también todas buscan su unidad, sin la que no pueden existir. Pues en tanto existe una cosa en cuanto que es una. Por eso vemos cómo todas las cosas se resisten en la medida de lo posible a ser divididas; y cómo no se separan los elementos componentes de cada una de ellas, a no ser por defecto de la misma cosa. Esta es la razón de que la meta del que gobierna una multitud sea la unidad o la concordia. Ahora bien, la causa de la unidad es lo que es uno esencialmente. Está claro que muchos no pueden unir y concordar cosas diversas si ellos mismos no están de algún modo unificados. Por otra parte, lo que es uno esencialmente, puede causar la unidad mejor y más propiamente que muchos unidos. Por eso, la multitud es mejor gobernada por uno que por muchos. Por lo tanto, el gobierno del mundo, que es el mejor, está bajo un solo gobernante. Esto es lo que dice el Filósofo: Los seres se resisten a ser mal gobernados; y el mando de muchos no es bueno, debiendo, por tanto, ser uno solo el gobernante". 
en razón de un bien ulterior. Los fines de las cosas pueden ser próximos o inmediatos, intermedios y fin último o absoluto. Los fines intermedios no se justifican en sí mismos, sino que son fines en razón de un fin ulterior o último: sin ese fin último nada se justifica, nada tiene razón de ser. Por otro lado, los fines son objetivos si se consideran en abstracto, o subjetivos, cuando un sujeto concreta esos fines objetivos para su vida.

La máxima unidad de hecho y de derecho que se puede dar al ordenamiento jurídico viene por la vía de la causa final no inmediata. Como dijimos, los fines admiten una gradación en la medida en que se acerquen al fin último humano: los medios apuntaban directamente a los fines próximos, estos miran a los intermedios, estos a su vez a los remotos, y estos se justifican en el fin último. Comenzamos el análisis hablando de las causas más inmediatas, para remontarnos a las que lo son menos.

En cuanto a las causas inmediatas de lo jurídico tenemos que: a) la relación jurídica mira al pago de lo justo; b) el derecho-subjetivo (que es una facultad para...) se da para exigir, poseer o ejercitar alguna cosa justa; c) la ley positiva tiene por objetivo inmediato el de crear una cierta medida de lo justo en los casos regulados; y, d) el Derecho-relación tiene su razón de ser metafísica en la sustancia humana, porque en ella inhiere y, desde otro punto de vista, tiene también por causa final inmediata determinar el pago de lo debido en cada caso concreto. Estas finalidades tan inmediatas y tan numerosas, dificilmente unifican el ordenamiento jurídico, pudiendo a lo sumo solo unificar un sector o rama del derecho.

$\mathrm{El}$ análisis de los fines próximos e intermedios del derecho debe ser más matizado. La ley tiene por causa próxima lo políticamente conveniente en cada tiempo y lugar, y por causa intermedia el bien común. ${ }^{41}$ De hecho, el bien común subjetivo (el bien común de cada sociedad, que a nivel estatal en buena parte está definido por las leyes superiores del país) es un importantísimo factor de unidad del sistema jurídico. ${ }^{42}$ En cambio, las causas próximas e intermedias del Derecho-relación (y del Derecho-subjetivo a través suyo) son los fines que la inteligencia, las potencias de la realidad corporal y la voluntad humana marcan a cada cosa. La inteligencia descubre para qué sirven las cosas, cuál es su finalidad; la realidad evidencia su ser potencial, aquello por donde se puede crecer y llegar a un fin superior (nadie tiene por fin lo que excede a sus potencias); por último, la voluntad determina qué camino seguir para llegar al fin, sancionando leyes, realizando actos jurídicos, suscribiendo contratos, etc. Además, los fines intermedios del Derecho-relación tienden lejanamente hacia el bien común de la sociedad. En consecuencia, un buen grado de coincidencia

41 Una acertadísima noción de bien común lo define como "el conjunto de condiciones de la vida social que hacen posible a las asociaciones y a cada uno de sus miembros el logro más pleno y más fácil de la propia perfección”; Concilio Vaticano II, Gaudium et spes, n. 26. La definición dada puede aplicarse sin inconvenientes al campo metafísico.

42 Una postura cercana a la escrita es la de Dworkin, quien pone como fundamento de la unidad del orden jurídico y legal a la "unidad de valores" de una sociedad. Cfr. Ronald Dworkin, "Justice for Hedgehogs”, Boston University Law Review, 90 (2) (2010), pp. 469-478. En su pensamiento, el derecho es solo "una rama, o subdivisión, de lo políticamente moral". 
se da entre los fines próximos e intermedios de la ley, del Derecho subjetivo y del Derecho-relación. Como estos fines abarcan sectores más amplios que los de la realidad mental e intencional, por eso son capaces de unificar en mayor grado el ordenamiento jurídico.

Y como el fin más alto unifica más, el fin último de la persona humana será el que mayor grado de cohesión proporcione al ordenamiento jurídico, a las leyes vigentes, al derecho-relación, a los derechos subjetivos y a cualquier género y número de relaciones jurídicas. Es preciso que haya un fin último humano para que pueda existir un ordenamiento jurídico de la humanidad. Sin él, los derechos humanos carecen de sentido: no pasan de ser postulados escritos, vociferados y hasta aplaudidos, pero que se quedarán en meros postulados o entes de pura razón, a los que les falta una razón última de ser.

La naturaleza del fin último del ser humano in genere es indiscutida: es la felicidad, la vida feliz de Aristóteles, el sumak kawsay de los indigenas andinos, "la vida realizada" de los filósofos clásicos, "la vida digna" de los juristas modernos y contemporáneos. Mas no siempre se coincide en qué sea aquello que hace feliz al ser humano. Metafísicamente observamos que nadie se realiza más allá de sus posibilidades: solo se puede llegar a ser, lo que hoy se es en potencia, como por ejemplo, un niño no espera ser a futuro un halcón o una ballena, sino una persona adulta. Las potencias humanas marcan los fines humanos (la vista, ver; la inteligencia, conocer; el tacto, tocar, etc.);43 las potencias más altas marcan los fines más altos. Hay un orden en las potencias humanas que se palpa cuando estas se dañan: no es lo mismo perder el tacto que el oído, el gusto que la vista... ${ }^{44} \mathrm{La}$ infelicidad más profunda para el ser humano consiste en perder lo más alto que puede alcanzar (la verdad y el amor de amistad), aunque se tenga todo lo inferior. Así, el ebrio que tiene todos los sentidos embotados pero no es capaz de razonar está menos realizado como persona y se parece más a un animal, que el sabio que sufre alguna incomodidad..$^{45}$

43 Varios iusnaturalistas contemporáneos han estudiado cómo la naturaleza humana y sus potencias determinan cuáles son los fines humanos "últimos", "necesarios” o "existenciales". V. gr. Johannes Messner, Ética social, politica y económica a la luz del derecho natural, Madrid, Rialp, trad. J. L. Barrios Sevilla, J. M. Rodríguez Paniagua y J. Enrique Diez, 1967, pp. 38-39; Robert Spaemann, Crítica de las utopías politicas, Pamplona, Eunsa, 1980, pp. 115 y ss.; Cfr. Germain Grisez, Joseph Boyle y John FinNis, "Practical Principles, Moral Truth, and Ultimate Ends", en The American Journal of Jurisprudence, 32 (1987), pp. 99-151. Estos autores, siguiendo la linea aristotélica-tomista, muestran la importancia de delimitar los fines humanos para dar un sentido al derecho y la moral. En cambio, a nosotros nos interesa el tema para evidenciar cómo tales fines son una causa —quizá la principal, pero no la única- de la unidad y el orden del sistema jurídico.

44 Las grandes culturas lo han intuido, y los grandes filósofos se han dedicado in extenso a definir cuál es el fin último (la vida feliz, la buena vida, la vida realizada) del ser humano (v. gr. Aristóteles, Tomás de Aquino, Abba, Rhonheimer, Finnis, etc.) mediante un análisis semejante al aquí realizado.

45 El fin último no puede estar determinado por los apetitos carnales y caducos, sino por las potencias espirituales: la inteligencia y la voluntad. Por eso los griegos ponían el fin último en la contemplación de la verdad y el cristianismo añadió el amor al Bien Supremo. Polo llegará a decir que si la voluntad humana que tiende al infinito tiene algún sentido, Dios existe (cfr. Leonardo Polo BARRENA, Quién es el hombre, Madrid, Rialp, 1991, pp. 224-225); si no, el ser humano sería lo que dice Sartre: "una pasión inútil". Pero el fin último no es el único que hay que alcanzar. El resto de fines humanos - uno por cada potencia - son fines medios, que conviene satisfacer medianamente para lograr 
Por cualquiera de las cuatro causas analizadas se concluye que la base más fundamental y decisiva de la unidad del sistema jurídico es la persona humana: ella es la base material del sistema jurídico, es quien le da forma, es el agente del derecho y, sobre todo, es la que con su naturaleza marca los fines del mundo jurídico. Desde otro punto de vista, hace falta un principio de unidad fuerte para que el ordenamiento sea compacto y coherente, y ontológicamente la unidad más fuerte en el universo es la unidad propia del acto de ser personal: solo ella puede dar una fuerte cohesión al ordenamiento jurídico. ${ }^{46}$

Existe una interesante relación entre las causas que unifican el ordenamiento jurídico y las fuentes del derecho. En realidad, son las mismas: los principios de unidad son las cuatro causas metafísicas estudiadas y, a su vez, estas cuatro causas metafísicas son también las fuentes del Derecho. ${ }^{47}$

El ordenamiento jurídico de un país también encuentra su unidad en la persona humana, pero añade otros principios de unidad más circunstanciales: unas mismas autoridades, una norma suprema común que subjetiviza los fines y valores objetivos (v. gr. la constitución), unas reglas homogéneas para todos, un grupo de ciudadanos con similares características, circunstancias, historia, etc. Por estos principios circunstanciales de unidad es posible distinguir los ordenamientos jurídicos de los diferentes países, mientras por la unidad de la persona humana es posible establecer lo común que hay entre los diferentes ordenamientos estatales y arribar a nociones como las de ius cogens, Derecho global o Derecho natural.

Pero aún resulta posible encontrar un apoyo más último, más fuerte y más completo de la unidad del sistema jurídico global, que rige no solo sobre las personas, sino también sobre las cosas. Como vimos, las cosas también son "jurídicas" en cuanto están relacionadas con el mundo del derecho. Por tanto, para encontrar el principio de unidad último del orden jurídico hemos de remontarnos a la causa de las personas y de las cosas. Tomás de Aquino decía que Dios es uno por su simplicidad, por su infinita perfección y

... por la unidad del mundo. Todo lo existente está íntimamente ordenado, ya que unas cosas sirven a las otras. Las cosas diversas no convergerían en un orden a no ser que fueran ordenadas por uno. Pues lo múltiple se coordina mejor dentro del orden que establece uno al que establecen muchos ya que el uno es causa de unidad,

la vida feliz. La meta final del camino no se alcanza sin metas medias. En este sentido, la filosofia clásica observaba que es necesario un minimo de bienestar humano para que pueda alcanzar sus fines más altos. Y este conjunto de fines satisfechos conforman la felicidad.

46 Según la antropologia, la unidad radical del ser humano se apoya en su acto personal. Este acto personal es un intenso acto de ser capaz de unificar forma sustancial, accidentes, actos, hábitos, etc. y darle un sentido. La dignidad humana, que es el fundamento para muchos de los derechos humanos, justamente se predica del acto intenso y perfecto de ser de la persona, que vale más que el de otros entes; de hecho, frente a la persona metafisicamente el resto de entes son "cosas" $u$ "objetos" del derecho.

47 Sobre la identificación de las fuentes del derecho con las cuatro causas, véase mi artículo Juan Carlos Riofrío Martínez-Villalba, "Las causas metafísicas como fuentes del derecho", Revista Telemática de Filosofia del Derecho, 15 (2012), pp. 259-308. 
mientras que lo múltiple lo es solo accidentalmente, esto es, en cuanto de algún modo es uno. Así pues, como quiera que aquello que es primero es, en cuanto tal, lo más perfecto y no accidentalmente, es necesario que lo primero a lo que se reduce todo en un orden sea uno solo. Y esto es Dios. ${ }^{48}$

En consecuencia, el fundamento absolutamente último de todo orden también del jurídico es Dios. Sin Dios no hay ni derecho, ni orden jurídico. O dicho al revés: si hay un orden jurídico, si verdaderamente hay un derecho, Dios existe. ${ }^{49}$

Alguno podría preguntarse, entonces, acerca de ciertos ordenamientos jurídicos humanos que no parecen tener su causa en Dios, como los regimenes jurídicos instaurados por Hitler, Stalin o cualquier tirano. Habría entonces que ratificarse en lo dicho: tales sistemas de leyes injustas no son Derecho, justamente por estar desorientados, desorganizados, por no buscar adecuadamente los fines humanos mediatos, ni últimos. De hecho, ni siquiera cabría calificar a tales regimenes de injustos, absurdos o ilegitimos sino apelásemos a un principio de justicia de orden superior.

\section{EL ORDEN DEL ORDENAMIENTO JURÍDICO}

Sea cual fuere la definición más conveniente de "ordenamiento jurídico”, ${ }^{50}$ parece indiscutible que por ser un "ordenamiento" deberá tener algún "orden”. Una buena definición de orden la encontramos en Ramírez, para quien:

... el orden consiste esencialmente en una relación entre varias cosas, distintas y desiguales, pero con alguna conveniencia entre ellas, que se relacionan, ante todo, con algo único y primero, o sea, con un principio, según un antes y un después, o según más o menos; de suerte que la correlación o coordinación entre sí de los distintos miembros de cada orden es secundaria, y depende de la relación primordial de todos ellos respecto del principio primero o máximo, dentro de ese orden. ${ }^{51}$

Como se ve, la misma noción de orden exige la presencia de algún principio ordenador.

48 Suma Teológica, I, q. 11, a. 3, sol. La quinta vía, conocida como el argumento de la finalidad o del orden, es formulada por Santo Tomás en varios lugares más: Suma Teológica, I, q. 2, a. 3; Summa contra gentes, 1. I, c. 13 y c. 42 .

49 La quinta vía tomista de la que hablamos, básicamente se puede sintetizar de la siguiente manera: a) vemos que los seres que carecen de conocimiento, como los cuerpos naturales, obran por un fin (porque suelen obrar del mismo modo para alcanzar lo mejor, lo cual no se da por azar, sino que por una intención llegan al fin); b) pero sucede que los seres que no tienen conocimiento no tienden a un fin, sino que son dirigidos por algún ser cognoscente e inteligente, como la flecha es dirigida por el arquero; c) además sucede que la serie de los seres inteligentes directores — que a su vez son dirigidos y ordenados - no puede proceder al infinito; d) en conclusión, debe existir un Ser Supremo inteligente por el cual todas las cosas naturales se ordenan a su fin. Muchísimos manuales de metafísica hablan de esta causa. V. gr. Ángel González Álvarez, Tratado de Metafisica, Madrid, Gredos, 1968, pp. 267-281. En síntesis, si existen fines existe un orden en el universo, y si existe un orden universal existe Dios.

50 Vid. nota 1.

51 Santiago Ramírez, De ordine placita quaedam thomistica, Salamanca, San Esteban, 1963, p. 16. 
Al igual que no hay unidad sin principio unificador, tampoco hay orden sin un principio ordenador que causa ese orden. De hecho, ambos principios están estrechamente relacionados y coinciden en buena medida. Tomás de Aquino, al hablar de la causalidad de este principio ordenador, observaba que "lo que es lo primero en cada orden" es "causa de todo lo que en dicho orden viene después". ${ }^{2}$ Con lo cual, ya podemos relacionar el principio ordenador con las fuentes del derecho (= cuatro causas metafísicas), y ellas con el principio unificador del ordenamiento jurídico (que dijimos que eran las mismas cuatro causas clásicas). Pero conviene ir un poco más despacio en este profundo asunto.

Los principios ordenadores pueden ser reales o lógicos (de mera razón). Los reales se basan directamente en la realidad de las cosas y comprenden las cuatro causas clásicas (material, formal, eficiente y final). En cambio, los principios lógicos, que copian de alguna forma la estructura de la realidad, dan algún orden mental a las cosas con una relación que no necesariamente se reproduce en la realidad. A la metafísica jurídica le interesan más los principios reales que los lógicos.

Ya hemos analizado cómo las cuatro causas clásicas son capaces de unificar el ordenamiento jurídico, cada una a su modo; sería un absurdo pretender que la causa material unifique con el mismo grado y fuerza el orden jurídico, que la causa eficiente. Hay que decir, además, que dentro de todos los principios ordenadores adquiere especial relevancia la causa final que, como dicen los clásicos, es la causa causarum que justifica en último término toda la causalidad. No en vano decía el Aquinate que "la esencia del orden proviene del fin". Todo orden tiene una causa final. No hay orden sin fin, ni ordenamiento jurídico sin fin humano.

Estas básicas nociones metafísicas fueron atacadas constantemente por Kelsen, quien fue "decididamente antifinalista". ${ }^{33}$ Pero es impensable un orden sin principio ni fin. Quien entiende bien las máximas metafísicas simplemente no puede concebir un sistema jurídico sin fines. Sin un fin el orden que pudiera conseguir el ordenamiento jurídico sería muy precario, carente de todo sentido: una sería una agregación como la de las arenas de la playa o la de los sacos apilados de cemento, estaríamos ante una multiplicidad de normas, derechos, relaciones o formas jurídicas que quién sabe por qué suerte les ha tocado estar una al lado de la otra. A lo sumo, se lograría un orden formal donde "todo coincide" o, más propiamente, "tiende a coincidir" y un injustificado orden eficiente, porque el agente produciría el derecho sin motivo alguno: accionaría, operaría, haría cosas como un loco sin un motivo final. Kelsen logró desarrollar en su Teoría pura del derecho un orden de este estilo, puramente formal; con el influjo de Merkl y la aparición de la nomodinámica, se ahondó algo en el orden dado por la causalidad eficiente, sin reparar que no hay orden eficiente, ni formal, si detrás no hay un fin que mueva a

52 Suma Teológica, I, q. 105, a. 3, sol.

53 Errázuriz, La teoría pura del derecho de Hans Kelsen, op. cit., p. 97. Como contrapunto, al hablar del Estado como lugar de "imputación" o "finalidad" del orden jurídico (ver cita hecha a nota 23) Kelsen parecería estar hablando de la causa final. En realidad ahí parece referirse más a la causa agente. En cualquier caso, sería un error de bulto considerar que el Estado o la norma son fines de la persona humana: en realidad, ellos son medios o instrumentos para lograr la realización de la persona. 
actuar y a ser de un modo determinado. Ante estos olvidos la metafísica recuerda que las causas están intrínsecamente interconectadas entre sí: "el fin mueve al agente, el agente educe la forma, y la forma organiza la materia”. ${ }^{54}$

Otra persona que descuidó la causa final en el derecho fue Luhmann, quien con gran coherencia dedujo que en el sistema jurídico (que para él estaba unido solo por la producción normativa, no por ningún fin) era prácticamente imposible que existiera un orden. ${ }^{55} \mathrm{En}$ el fondo, su concepción ilimitadamente abierta del orden jurídico (donde cualquier cosa pensada puede ser Derecho) le impide apreciar que la producción de normas tiene un sentido, un fin humano que es el que organiza todo el sistema.

Pasarán los años y aparecerán movimientos como el del neoconstitucionalismo, "nuevo" quizá por desear superar la visión kelseniana que destacará que los fines básicos del ser humano juegan un papel de primera categoría en el Derecho. La forma, el texto escrito de la norma (aunque sea la misma constitución) pasará a considerarse como "medio" o "instrumento" que facilita alcanzar los verdaderos derechos de las personas. El neoconstitucionalismo quita los acentos de la causa formal del derecho que en ocasiones queda totalmente olvidada y los pone en la causa final, que para sus defensores ostenta una primacía absoluta. ${ }^{56}$ También se procura atender a la causa material del derecho: se mira más la realidad del pobre que sufre, que "el derecho a no sufrir" formalmente consagrado en el texto constitucional.

En general, hoy se acepta ampliamente la existencia de unos fines en el derecho y en el ordenamiento jurídico. Se discute, sin embargo, cuáles son y qué naturaleza tienen. Los positivistas a ultranza seguirán diciendo que el único fin jurídico es el fin objetivo de la ley (ley fundamental, si se quiere); otros anclarán los fines

54 Tomás Alvira, Luis Clavell y Tomás Melendo, Metafisica, Pamplona, Eunsa, 1986, p. 229.

55 "The common denominator for all these different problems may lie in the fact that the evolution of the social system makes possible the establishment of a highly improbable order, an order which is full of preconditions. The combination of normative closure and cognitive opennes discussed above is one of these improbabilities"; Luhmann, "The Unity of the Legal System", op. cit., p. 32.

$56 \mathrm{El}$ neoconstitucionalismo es un movimiento nacido en Europa, que toma elementos de diferentes culturas jurídicas. Cfr. Robert ALEXY, "Los derechos fundamentales en el estado constitucional democrático”, en Miguel Carbonell (ed.), Neoconstitucionalismo, España, Trotta, 2003; Miguel CARBonELl y Leonardo GARCíA, El canon neoconstitucional, Bogotá, Universidad Externado de Colombia, 2010. En el fondo, se busca el fin del derecho, la efectiva vigencia de las normas que consagran derechos ("vigencia material" dicen los autores del movimiento, en contra de la "vigencia formal" propugnada por los positivistas). Cfr. Jose Luis Serrano, Validez y vigencia, Madrid, Trotta, 1999, p. 56; Juan Montaña Pinto y Patricio PAZmiño Freire, "Algunas consideraciones acerca del nuevo modelo constitucional ecuatoriano”, en J. Benavides y J. Escudero (eds.), Manual de justicia constitucional ecuatoriana, Quito, Cedec, 2013, p. 25.

Los neoconstitucionalistas más extremos incluso aceptarán que se puede interpretar la constitución en contra de la misma constitución, para salvaguardar los valores sociales o los derechos de la persona. Así, "para el neoconstitucionalismo, la indeterminación semántica es un problema secundario, pues la Constitución no es un artefacto lingüístico y comunicativo, sino una entidad ideal, axiológica, cuya materialidad y concreción son tan independientes en gran medida de las palabras y, por tanto, no sometidas a los límites denotadores y conformadores de estas"; Juan Antonio García AмADo, "Derechos y pretextos. Elementos de crítica al neoconstitucionalismo", en M. Carbonell (ed.), Teoría del neoconstitucionalismo, Madrid, Trotta, 2007, p. 242. 
en los valores sociales, en la "voluntad general", o en otros raros elementos que Kelsen calificaba de "metajurídicos" y que no darán más que una forzada unidad al sistema jurídico. Más problemas tendrán los que ven al derecho en términos subjetivistas, quienes desde su visión atomista corren el peligro de caer en un anarquismo que no acepta ninguna ley, ni autoridad superior que dé unidad al sistema jurídico (olvidando la unidad y el orden que proporciona la causalidad eficiente común). Por su parte, los iusnaturalistas tenderán a dar una unidad y orden fuerte al ordenamiento cimentándolo en la única naturaleza humana (en sus fines naturales, inclinaciones, potencias, etc., dependiendo del autor), pero si descuidan el resto de principios de unidad, habrán dado un mal servicio al derecho. Aquí, la metafísica vuelve a arrojarnos luz: si el derecho es eminentemente humano, y como vimos antes, el ser humano no puede tener más fines que los que permiten sus potencias espirituales y corporales, luego los fines últimos del derecho no pueden ser otros que los mismos fines que posibilita la naturaleza humana. El alimento no es un derecho subjetivo protegido por la ley porque así lo dice la constitución, la sociedad o la voluntad general: lo es porque así lo determina la naturaleza. Habrá que añadir, por lo demás, que no todas las potencias son igualmente importantes: no se valora igual la pérdida de un ojo, que la de un dedo, que la serenidad para pensar o la capacidad para amar. Un ser viviente que carece de inteligencia no es un ser humano, sino un animal o una planta. De la jerarquía de las potencias naturales deriva la jerarquía de los fines humanos, que son también los fines jurídicos.

A la indisoluble relación metafísica que existe entre potencias humanas y fines humanos, se pueden añadir otras relaciones más. Las potencias humanas no solo marcan los fines, sino que también determinan cuáles son los valores del derecho, los bienes jurídicos y los primeros principios del derecho. Valor es aquello que se estima como bueno, ${ }^{57} \mathrm{y}$ el bien humano solo puede ser aquel ente concreto capaz de configurarse como fin de las potencias humanas. No es bueno para el ser humano planear como los pájaros, ni enterrarse en la tierra como un topo, pues su naturaleza no le ofrece esas posibilidades. Y de los fines, valores y bienes humanos nacen los primeros principios de la actuación, que no son sino aquellas guias para la realización personal, para conquistar lo bueno y lo valioso, los fines de la persona humana. De ahí la intrínseca relación que existe entre potencias-finesbienes-valores-primeros principios.

Sucede, además, que el ser humano es solo uno. Por ello, esos fines humanos, esos valores y primeros principios serán también los fines del ordenamiento jurídico, los valores jurídicos y los primeros principios del derecho. Obtenemos así la fórmula que liga las potencias humanas-fines-bienes-valores-primeros principios del derecho, que organiza a radice el ordenamiento jurídico, con el mismo orden jerárquico de las potencias humanas. Nuevamente, la naturaleza humana con todas sus potencialidades es el elemento más integrador del Derecho.

57 Seguimos aquí a Hervada, para quien "el valor es la estimación del ser como bien, que obedece a una dimensión objetiva y real del ser”; Hervada, Lecciones propedéuticas, op. cit., p. 68. 


\section{CONCLUSIONES}

Sintetizando los hallazgos a los que hemos llegado, tenemos lo siguiente:

1. En primer lugar, que el ordenamiento jurídico posee intrínsecamente una fuerte "unidad de orden".

2. Tal unidad y orden se fundamentan en las cuatro causas metafísicas de la realidad (material, formal, agente y final). Dentro de ellas cobra primacía la causa final.

3. Los pocos autores que han tratado acerca de la unidad y del orden del ordenamiento jurídico se han focalizado en una o dos causas, descuidando las demás. En concreto, los neokantianos tienden a poner el orden jurídico en la base material de la conciencia, intelecto, etc., donde está el "deber ser". Kelsen, Merkl, y el positivismo normativo en la causa formal, y algo en la causa eficiente. Luhmann, con su teoría de la autopoiésis del ordenamiento jurídico, pone la unidad en la producción normativa (causa eficiente), pero niega el orden del sistema. El neoconstitucionalismo pone todos los acentos en el fin del ordenamiento: los derechos subjetivos de las personas.

4. Las causas de unidad y orden del ordenamiento jurídico se verifican principalmente en: i) la virtud de la prudencia; ii) la fuerte unidad de la persona humana; iii) la sociabilidad propia de nuestra naturaleza que crea grupos humanos con mayor o menor cohesión; iv) las concepciones jurídicas generalizadas; v) la actuación jurídica más abstracta y general, como las leyes fundamentales; vi) las autoridades eficaces más altas, donde está en primer lugar la Suprema autoridad divina; vii) la fórmula potencias-fines-bienes-valores-principios humanos; y, viii) la jerarquía de las potencias humanas, que redunda en la jerarquia de los fines, valores y principios del derecho.

5. Una doctrina que no tome en cuenta todas las causas del ordenamiento jurídico resultará siempre incompleta.

\section{BiBLIOGRAFÍA}

Alchourrón, Carlos E. y Bulygin, Eugenio, "Sobre el concepto de orden jurídico", Crítica, 23 (8) (1976), pp. 3-23.

Alexy, Robert, "Los Derechos Fundamentales en el Estado constitucional democrático", en Miguel Carbonell (ed.), Neoconstitucionalismo, Madrid, Trotta, 2003.

Alvira, Tomás, Clavell, Luis y Melendo, Tomás, Metafisica, Pamplona, Eunsa, 1986.

Austin, John, The Province of Jurisprudence Determined, New York, The Noonday Press, 1954.

BoвBio, Norberto, Teoría General del Derecho, Bogotá, Temis, 1992. 
Calvo García, Manuel, Teoría del Derecho, Madrid, Tecnos, 2000.

CARACCIOlO, Ricardo, "Sistema jurídico", en Garzón Valdés, E. y Laporta, F. (eds.), Enciclopedia Iberoamericana de Filosofia, vol. 11, Madrid, Trotta, 1996.

Carbonell, Miguel y García, Leonardo, El canon neoconstitucional, Bogotá, Universidad Externado de Colombia, 2010.

CARPintero, Francisco, Historia del derecho natural. Un ensayo, México, UNAM, 1999.

Dworkin, Ronald, "Justice for Hedgehogs", Boston University Law Review, 90 (2), (2010), pp. 469-478.

Errázuriz Mackenna, Carlos José, La teoría pura del derecho de Hans Kelsen, Pamplona, Eunsa, 1986.

FariÑas Dulce, María José, "De la globalización económica a la globalización del derecho: los nuevos escenarios jurídicos”, Derechos y Libertades, 8 (2000), pp. 179-194.

Finnis, John M., Grisez, Germain y Boyle, Joseph, "Practical Principles, Moral Truth, and Ultimate Ends", en The American Journal of Jurisprudence, 32 (1987), pp. 99-151.

García Amado, Juan Antonio, "Derechos y pretextos. Elementos de crítica al neoconstitucionalismo”, en M. Carbonell (ed.), Teoría del neoconstitucionalismo, Madrid, Trotta, 2007.

García Miranda, Carmen María, "El principio de unidad en el concepto de ordenamiento jurídico de Norberto Bobbio", en Cuadernos electrónicos de filosofia del derecho, 1 (1998).

García Miranda, Carmen Maria, "La unidad en el concepto de ordenamiento jurídico de Santi Romano”, en Anuario da Facultade de Dereito da Universidade da Coruña, 2 (1998), pp. 287-298.

González Álvarez, Ángel, Tratado de Metafisica, Madrid, Gredos, 1968.

Hart, Hebert, The Concept of Law, Oxford, Clarendon Press, 1961.

Hervada Xiberta, Javier, "Reflexiones acerca de la prudencia jurídica y el derecho canónico", en Revista Española de Derecho Canónico, XVI (1961), pp. 415-451.

HERvadA XiberTa, Javier, Introducción crítica al derecho natural, Pamplona, Eunsa, 2001.

Hervada Xiberta, Javier, Lecciones propedéuticas de filosofia del derecho, $3^{\text {a }}$ ed., Pamplona, Eunsa, 2000.

Kelsen, Hans, "Zur Lehre vom öffentlichen Rechtsgeschäft", Archiv des öffentlichen Rechts, 31 (1913), pp. 53-98, 190-249.

Kelsen, Hans, Compendio de Teoría General del Estado, 1925, México, Colofón, 324 trad. de L. Recaséns Siches y J. de Azcárate, 2007.

Kelsen, Hans, Das problem der Souveränität, Tubinga, J.C.B. Mohr, 1920. 
Kelsen, Hans, Hauptprobleme, Tubinga, J.C.B. Mohr, 1923. Trad. de W. Roces, Problemas capitales de la teoría jurídica del Estado, México, Porrúa, 1987.

KELSEN, Hans, Reichgesetz und Landesgesetz nach der österreichischen Verfassung, en Archiv des öffentlichen Rechts, 32 (1914), pp. 390-438.

Kelsen, Hans, Reine Rechtslehre, $2^{\mathrm{a}}$ ed., 1960. Trad. de R. J. Vernengo, La teoría pura del derecho, 2a ed., México, UNAM, 1982.

Kucsko-Stadlmayer, Gabriele, "La contribución de Adolf Merkl a la teoría pura del derecho”, en Revista de la Facultad de Derecho de México (2005), pp. 243-258.

Luhmann, Niklas, "The Unity of the Legal System”, en G. Teubner (ed.), Autopoietic Law: A New Approach to Law and Society, Berlin-New York, De Gruyter, 1987, pp. 12-35.

Macintyre, Alasdair, Tras la virtud, Barcelona, Crítica, trad. de A. Valcárcel, 1987.

Manrigue Zegarra, César Edmundo, Breve estudio sobre la noción de orden jurídico, en Cuadernos de investigación y jurisprudencia, 6 (2007), pp. 1-33.

Messner, Johannes, Ética social, politica y económica a la luz del Derecho natural, Madrid, Rialp, trad. J. L. Barrios Sevilla, J. M. Rodríguez Paniagua y J. Enrique Diez, 1967.

Montaña Pinto, Juan y Pazmiño Freire, Patricio, "Algunas consideraciones acerca del nuevo modelo constitucional ecuatoriano”, en J. Benavides y J. Escudero (eds.), Manual de justicia constitucional ecuatoriana, Quito, Cedec, 2013.

Polo Barrena, Leonardo, Quién es el hombre, Madrid, Rialp, 1991.

Ramírez, Santiago, De ordine placita quaedam thomistica, Salamanca, San Esteban, 1963.

RAZ, Joseph, El concepto de sistema jurídico. Una introducción a la Teoría del Sistema Jurídico, México, UNAM, trad. de R. Tamayo, 1986.

Recasens Siches, Luis, Tratado general de filosofia del derecho, 6aㅗ ed., México, Porrúa, 1978.

Riofrío Martínez-Villalba, Juan Carlos, "Las causas metafísicas como fuentes del derecho”, Revista Telemática de Filosofia del Derecho, 15 (2012), pp. 259-308.

Romano, Santi, El ordenamientojurídico, Madrid, Instituto de Estudios Políticos, 1963.

Sancho Izguierdo, Miguel y Hervada Xiberta, Javier, Compendio de derecho natural, t. I, Pamplona, Eunsa, 1980.

Schmitr, Carl, Teoría de la Constitución, Madrid, Editorial Revista de Derecho Privado, 1934.

Serrano, José Luis, Validez y vigencia, Madrid, Trotta, 1999.

Spaemann, Robert, Crítica de las utopías políticas, Pamplona, Eunsa, 1980. 
Tomás De Aguino, Compendium theologiae ad fratrem Reginaldum socium suum carissimum, París o Nápoles, 1273 aprox., trad. de traducción de J. I. Saranyana y J. Restrepo Escobar, Compendio de Teología, Madrid, Rialp, 1980.

Tomas De Aguino, Suma Teológica. París-Italia, 1265-1272, trad. de AA.VV. (BAC), Suma Teológica de Santo Tomás de Aquino, 4ª ed., Madrid, BAC, 2001.

Ulloa Ortiz, Manuel, El orden jurídico, México D.F., UNAM, s.f.

Vilasojana Rubio, Josep Maria, Identidad del orden jurídico y régimen politico, Barcelona, Universitat Pomepu Fabra, 1993.

VILLEY, Michel, Los fundadores de la Escuela Moderna del Derecho Natural, Buenos Aires, Ghersi, trad. de C. R. Sanz, 1978.

Zuleta, Hugo R., "El concepto de orden jurídico en la teoría de Alchourrón y Bulygin”, en Análisis filosófico, 33-2 (2013), pp. 239-248. 